\title{
Study on the Temperature Effect on Regeneration of Iodide Form of Resin Into Multiatomic Anionic Forms
}

\author{
Ratnesh Kumar ${ }^{1}$, Ajay Kumar Mishra ${ }^{1} \&$ K. S. Seshadri ${ }^{1}$ \\ ${ }^{1}$ Department of Atomic Energy, Kalpakkam, Tamil Nadu, India \\ Correspondence: K. S. Seshadri, Department of Atomic Energy, Kalpakkam, Tamil Nadu 603 102, India. E-mail: \\ seshubestarts@gmail.com
}

Received: February 3, 2014 Accepted: June 8, 2014 Online Published: July 3, 2014

doi:10.5539/ijc.v6n3p29 URL: http://dx.doi.org/10.5539/ijc.v6n3p29

\begin{abstract}
The pressurized heavy water reactors make use of heavy water in moderator and in primary heat transport system. The cationic fission products produced during the reactor operation such as Cesium, Strontium, Cobalt, Palladium, Ruthenium and anions Iodide, Iodate, Ruthenate etc. contaminate the heavy water. Columns containing Ion exchange resins in on line are used for purification. In this purification process, the resins pick up activity and ionic impurities. It is imperative to treat the spent resin into innocuous form. Hence an attempt has been made to convert the Iodide containing spent resin into multi atomic anionic forms viz. chlorate, dichromate, permanganate and oxalate forms and study the role of temperature in the exchange reactions. The exchange reactions were found to be endothermic with enthalpies $170.79 \mathrm{KJ} / \mathrm{mole}$ for chlorate, $161.59 \mathrm{KJ} / \mathrm{mole}$ for dichromate, $119.68 \mathrm{KJ} / \mathrm{mole}$ for Permanganate and $83.07 \mathrm{KJ} / \mathrm{mole}$ for Oxalate.
\end{abstract}

Keywords: iodide, chlorate, dichromate, permanganate, oxalate, enthalpy

\section{Introduction}

Spent resins are generated in purification of primary heat transport system, moderator system, and spent fuel storage pond water. The spent resin containing cationic and anionic fission products is disposed in the radioactivity disposal area without treatment or fixed in cement or in thermosetting polymer as reported (Plecas et al., 2003). Direct immobilization in thermosetting resin, cement etc. results in final product whose volume is more than that of the original waste form. Incineration of spent resin involves burning at higher temperature (700 ${ }^{\circ} \mathrm{C}$ ) which entails problem of handling off gasses, corrosive fumes of $\mathrm{NOX}, \mathrm{SO}_{2}$ etc. and radioactivity from the resin. Also it does not result in complete burning and therefore results in tarry residue.

Acid digestion, the other alternate method, generates new kind of waste solutions and complicates the final disposal as reported (Miriam et al., 1982). Also it needs handling of concentrated mineral acids and handling off gasses viz. $\mathrm{NOX}, \mathrm{SO}_{2}$ etc. Wet oxidation did not completely oxidize organic carbon to carbon dioxide gas as reported (Kuobota et al., 1983).

Hence an attempt has been made to convert the spent resin into multi atomic anionic forms. Regeneration of spent resin into multi atomic anionic forms renders the handling of the almost non-active resin easy which can be fixed in cement or polymer safely.

Not much literature is available on the regeneration of spent resin into multi atomic anionic forms but there are literatures on the feasibility and conditions of conversion of one form of resin into another form (Vogel, 1978).

Since the regeneration of the spent resin can be efficiently carried out if we know the role of temperature on the regeneration, the experiments on the effect of temperature on the exchange of Iodide form of resin with multi atomic anions is relevant.

Results indicate that in the conversion of the Iodide form of the resin into multi atomic anionic forms, the equilibrium constant for the exchange reactions increases with temperature favoring the conversion at higher temperature.

\section{Experimental}

\subsection{Materials}

$\mathrm{OH}^{-}$form of anion exchanger of make Indion 850, porous weak base was used for the experiment. The resin is a 
high porosity weak base anion exchanger in bead form, containing tertiary ammonium groups, the structure of which is given below.

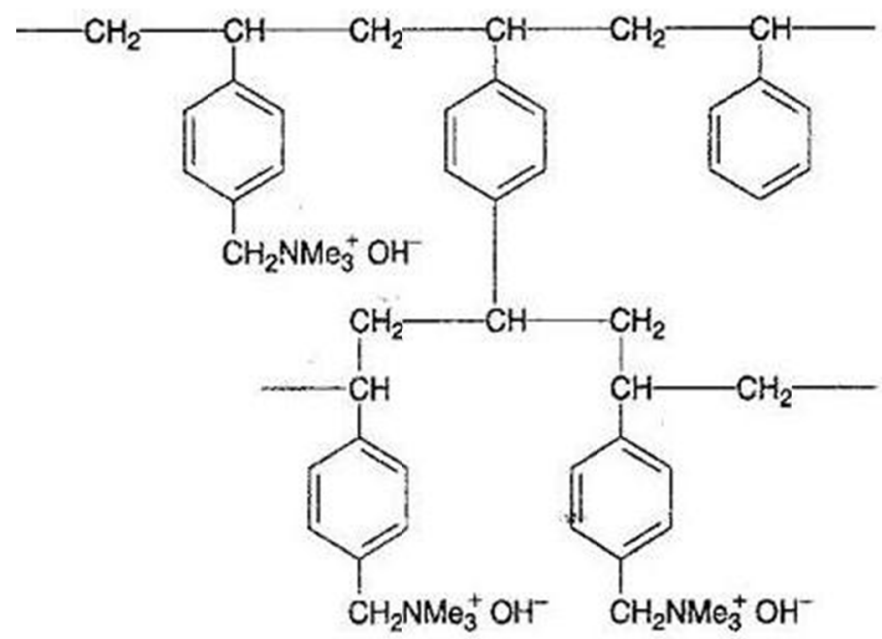

AR grade sodium Iodide was used for conversion of the resin into Iodide form of the resin.

AR grade potassium dichromate, potassium chlorate, potassium oxalate, potassium permanganate all procured from $\mathrm{M} / \mathrm{s}$. Merck were used for the experiment.

\subsection{Methods}

\subsubsection{Estimation of Exchange Capacity of Resin}

The exchange capacity of the ion exchanger was found out by equilibrating $10 \mathrm{gm}$ of the $\mathrm{OH}^{-}$form of the resin in $500 \mathrm{ml}$ of $3 \mathrm{~N}$ Sodium chloride solution and estimating the exchanged $\mathrm{OH}^{-}$titrimetrically using phenolphthalein indicator.

\subsubsection{Preparation of Nonactive Loaded Resin}

$50 \mathrm{~g}$ of $\mathrm{OH}^{-}$form of ion exchange resin was soaked in $500 \mathrm{ml}$ solution containing non active Iodide corresponding to $300 \%$ stoichiometric amount of exchange capacity. It was kept overnight, the supernatant drained and the resin was dried under IR lamp. The so prepared nonactive Iodide loaded resin was used for studying the effect of temperature on the exchange of Iodide loaded resin with multi atomic anions viz. dichromate (using potassium dichromate), chlorate (using potassium chlorate), Oxalate (using potassium oxalate) and permanganate (using potassium permanganate).

\subsubsection{Study on the Mechanism of Exchange of Iodide Loaded Resin With Multi Atomic Anions}

To elucidate the mechanism of exchange of multi atomic anions with anion exchanger, (whether it is particle or film diffusion controlled) interruption test (Friedrich Helfferich, 1962) was carried out. $5 \mathrm{~g}$ of Iodide loaded resins were allowed to exchange with $50 \mathrm{ml}$ of anionic solutions of $100 \%$ stoichiometry $(0.0616 \mathrm{~N})$ up to 40 minutes, then it was interrupted for 20 minutes by draining the solution from the resin and again allowed to recontact. The experiment was continued and the percentage regeneration before and after the interruption period was estimated and plotted as function of time (Figure 1). 


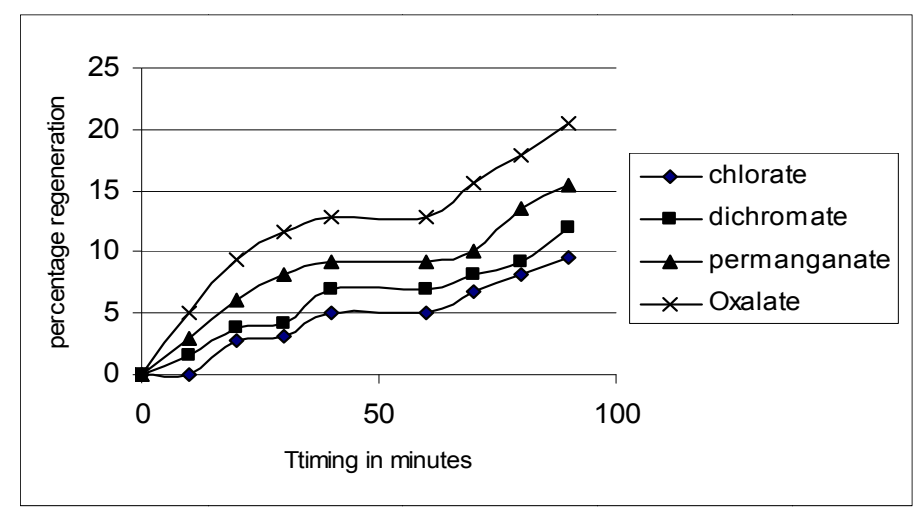

Figure 1. Study of mechanism on the regeneration of iodide loaded resin using multi atimic anions

The following schematic diagram explains the steps involved in the experimentation on the elucidation of mechanism of exchange of Iodide loaded resin with multi atomic anions.

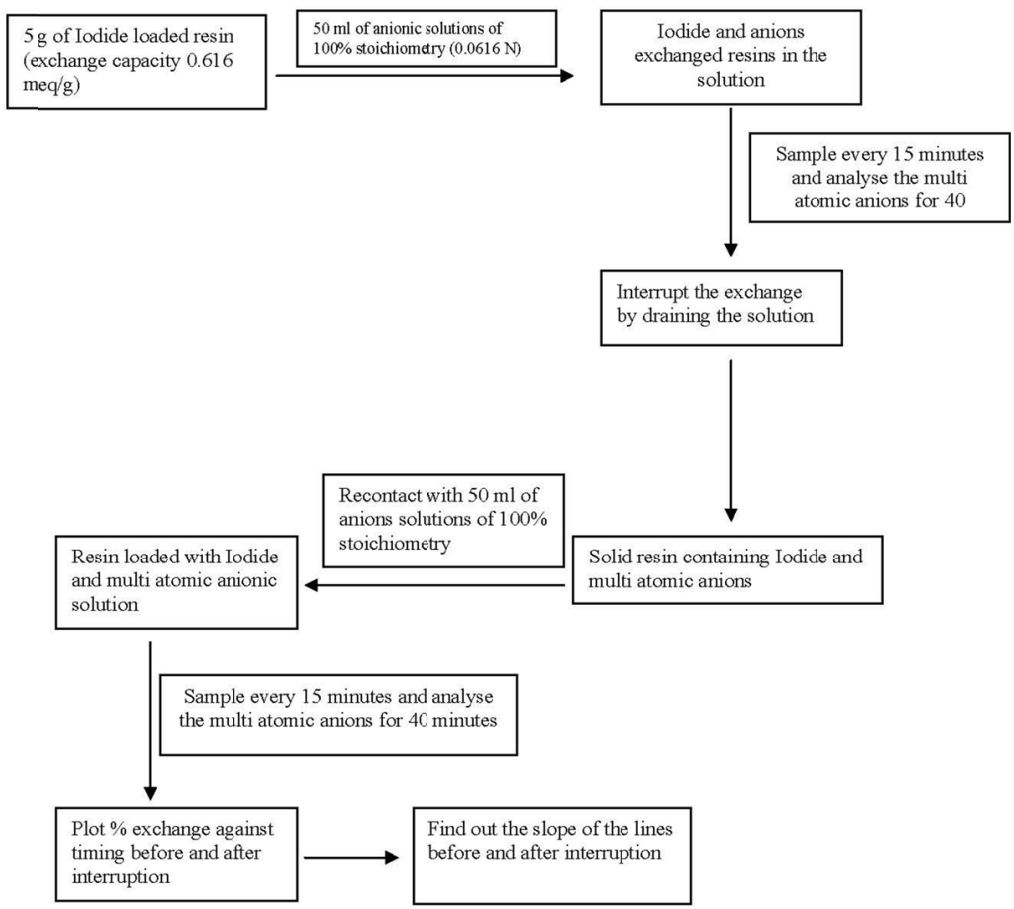

Schematic diagram on the experimentation of study on the mechanism of exchange reactions

\subsubsection{Study of Effect of Temperature on the Exchange}

$1 \mathrm{gm}$ of the Iodide form of the resins was equilibrated with $100 \mathrm{ml}$ of multiatomic anionic solutions viz. potassium chlorate, potassium dichromate, potassium permanganate and potassium oxalate solutions of strength $6.16 \mathrm{mN}, 12.32 \mathrm{mN}, 18.48 \mathrm{mN}, 24.64 \mathrm{mN}$ and $30.80 \mathrm{mN}$ corresponding to $100,200,300,400$ and $500 \%$ stoichiometric amount with respect to exchange capacity, at $303 \mathrm{~K}, 323 \mathrm{~K}, 343 \mathrm{~K}$ and $363 \mathrm{~K}$ by thermo stating for 1 hour.

The strength of the unexchanged multi atomic anions were estimated volumetrically from which quantity of exchanged Iodide in to the solution phase and the exchanged multi atomic anions into the resin phase were estimated knowing the exchange capacity as $0.616 \mathrm{meq} / \mathrm{g}$. The $\%$ conversion into multi atomic forms from the 
Iodide form of the resin was plotted against strength of multi atomic ions in solution at various temperatures (Figures 2a-2d).

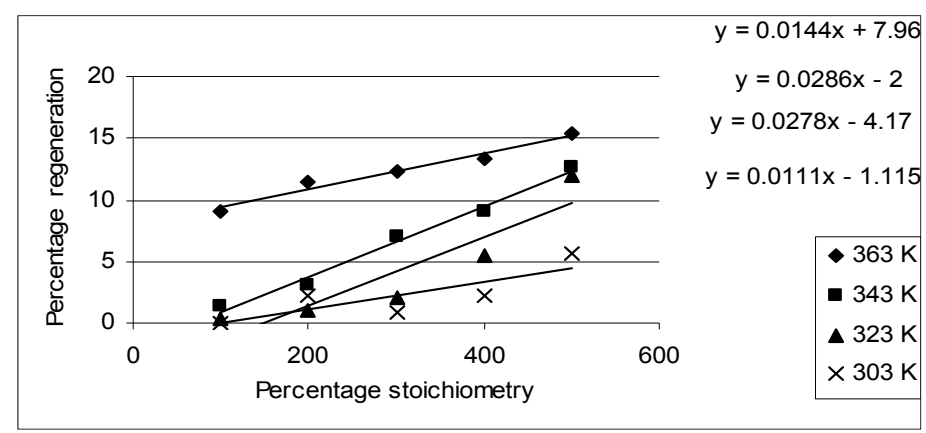

Figure 2a. Regeneration of Iodide form of resin into chlorate form at different temperatures

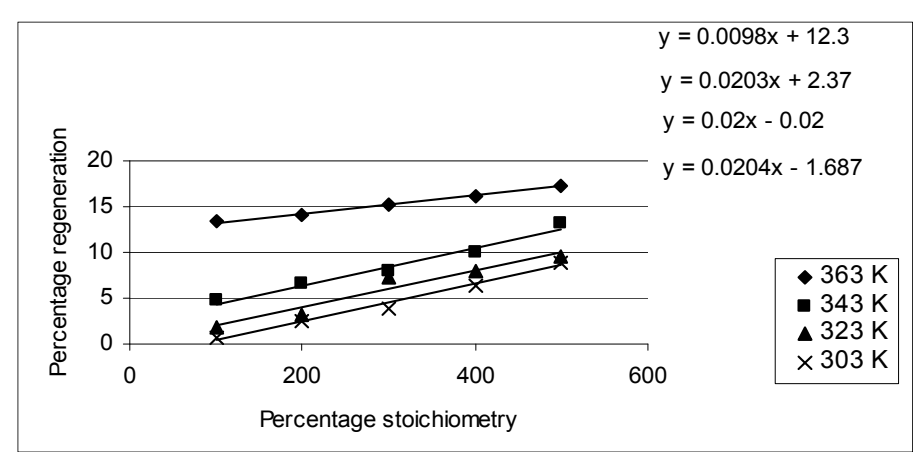

Figure $2 b$. Regeneration of Iodide form of resin into dichromate form at different temperatures

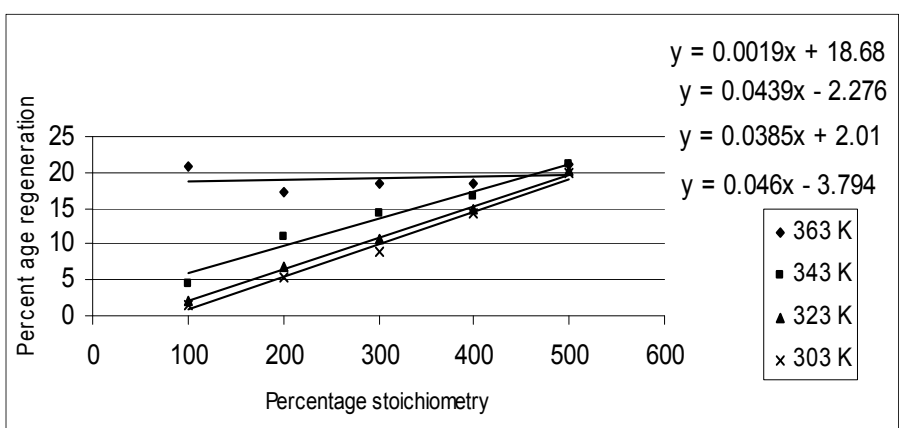

Figure 2c. Regeneration of Iodide form of resin into permanganate form at different temperatures

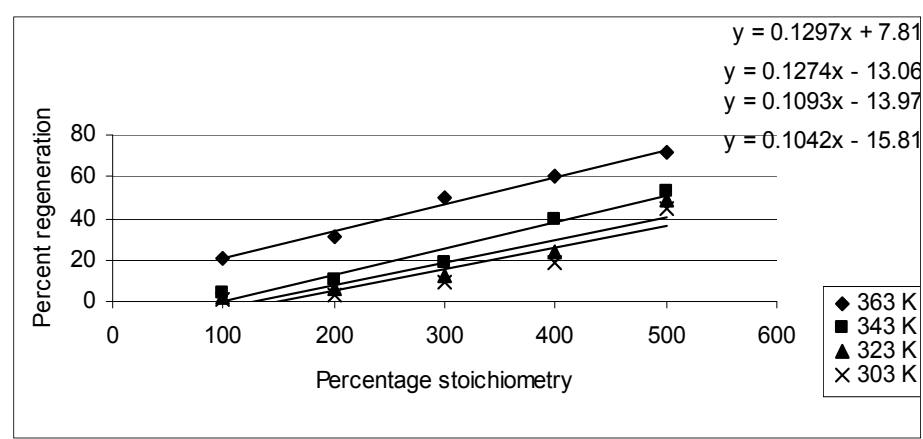

Figure 2d. Regeneration of Iodide form of resin into Oxalate form at different temperatures 
The apparent equilibrium constant at various temperatures $\left(\mathrm{K}_{\mathrm{app}}\right)$ were estimated from the strength of the unexchanged multi atomic ions in the solution phase, exchanged Iodide ion in the solution phase and the remaining Iodide and multi atomic ions in the resin phase obtained from the exchange capacity of the resin. Figures 3a-3d shows the plot of variation of $\log \mathrm{K}_{\mathrm{app}}$ of the exchange reaction with multi atomic ion concentration.

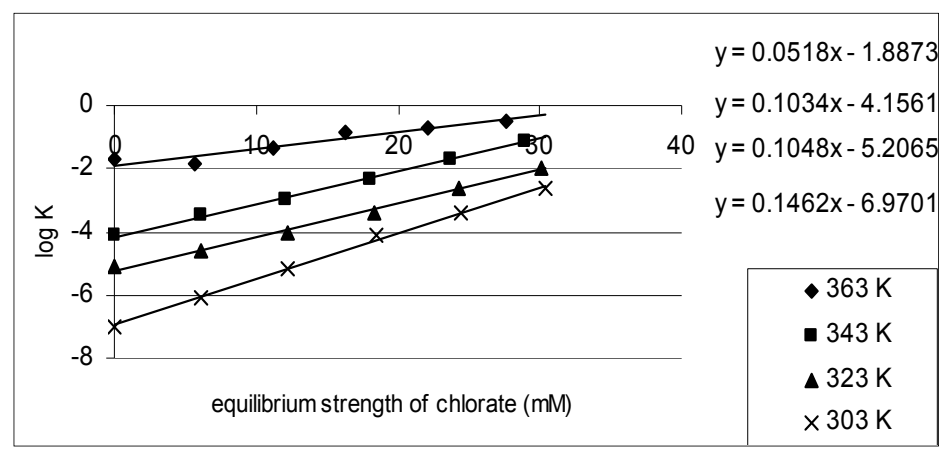

Figure 3a. Estimation of thermodynamic equilibrium constant in the Iodide-chlorate exchange

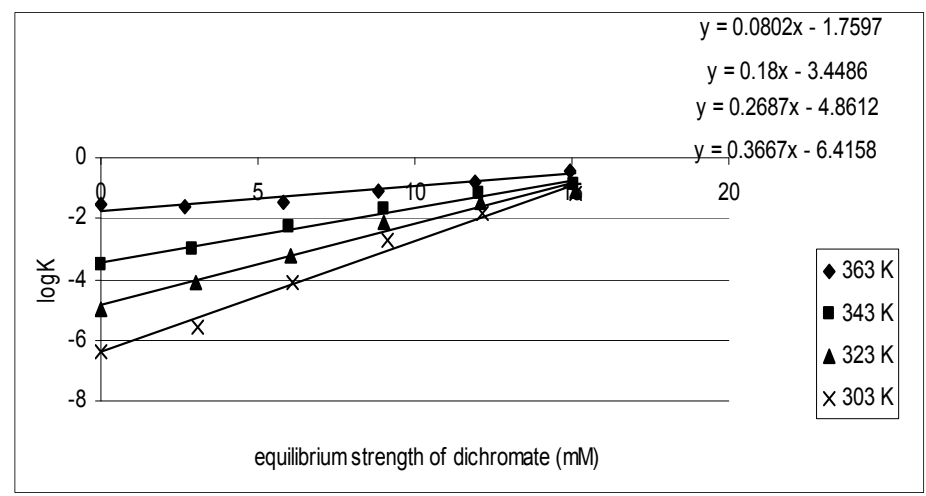

Figure 3b. Estimation of thermodynamic equilibrium constant in the Iodide-dichromate exchange reactions

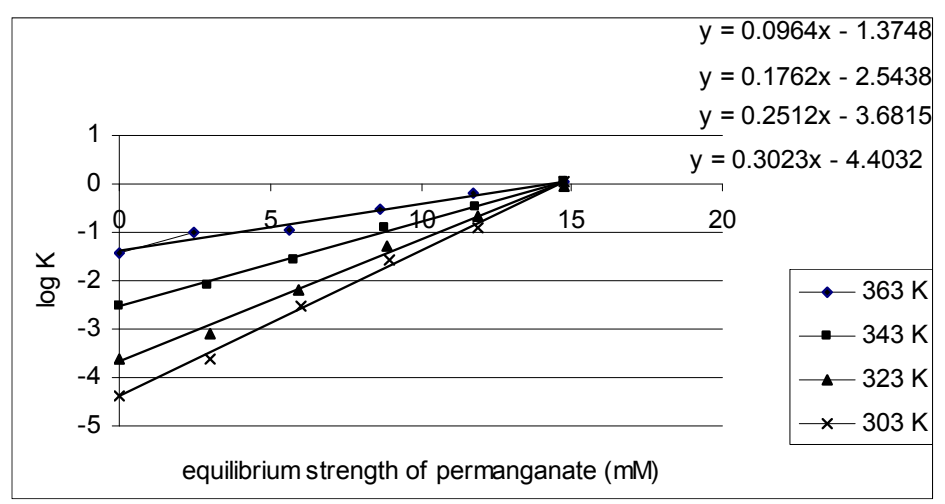

Figure 3c. Estimation of thermodynamic equilibrium constant in the Iodide-Permanganate exchange reactions 


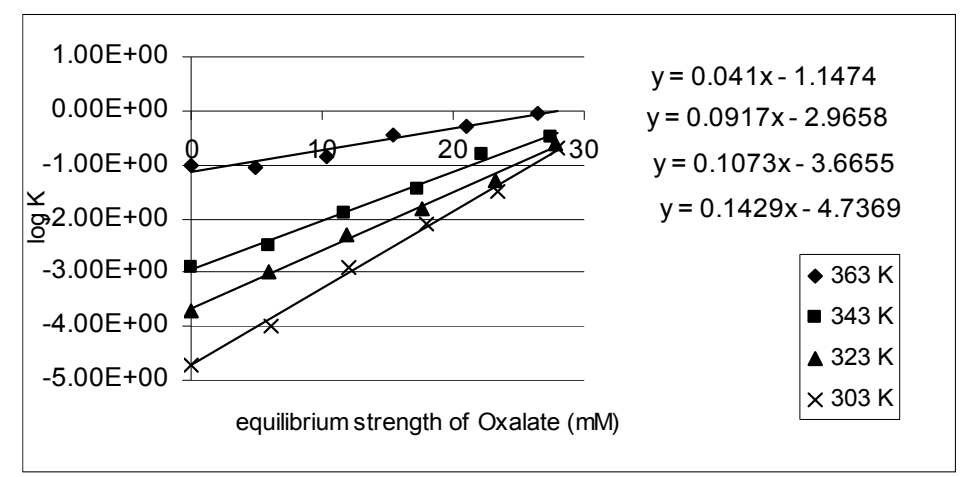

Figure 3d. Estimation of thermodynamic equilibrium constant in the Iodide-Oxalate exchange reactions

Tables 1a-1d give the thermodynamic equilibrium constants for the exchange reactions obtained by extrapolating the equilibrium constant against concentration of multi atomic ion to zero multi atomic ion concentration

Table 1a. Thermodynamic equilibrium constants of equilibrium reactions of chlorate ion with Iodide loaded resin at various temperatures

\begin{tabular}{cccc}
\hline & & \multicolumn{2}{c}{ Thermodynamic equilibrium constant } \\
\cline { 3 - 4 } S. No. & Temp K & $\log \mathrm{K}$ & $\mathrm{K}$ \\
\hline 1 & 303 & -6.9701 & $1.07 \times 10^{-7}$ \\
2 & 323 & -5.2065 & $6.215 \times 10^{-6}$ \\
3 & 343 & -4.1561 & $6.98 \times 10^{-5}$ \\
4 & 363 & -1.8873 & $1.30 \times 10^{-2}$ \\
\hline
\end{tabular}

Table $1 b$. Thermodynamic equilibrium constants of equilibrium reactions of dichromate ion with Iodide loaded resin at various temperatures

\begin{tabular}{cccc}
\hline \multirow{2}{*}{ S. No. } & Temp K & \multicolumn{2}{c}{ Thermodynamic equilibrium constant } \\
\cline { 3 - 4 } & & Log K & $\mathrm{K}$ \\
\hline 1 & 303 & -6.4158 & $3.83 \times 10^{-7}$ \\
2 & 323 & -4.8612 & $1.37 \times 10^{-5}$ \\
3 & 343 & -3.4486 & $3.55 \times 10^{-4}$ \\
4 & 363 & -1.7597 & $1.7 \times 10^{-2}$ \\
\hline
\end{tabular}

Table 1c. Thermodynamic equilibrium constants of equilibrium reactions of Permanganate ion with Iodide loaded resin at various temperatures

\begin{tabular}{cccc}
\hline & & \multicolumn{2}{c}{ Thermodynamic equilibrium constant } \\
\cline { 3 - 4 } S. No. & Temp K & $\log \mathrm{K}$ & $\mathrm{K}$ \\
\hline 1 & 303 & -4.4032 & $3.9 \times 10^{-5}$ \\
2 & 323 & -2.5438 & $2.8 \times 10^{-3}$ \\
3 & 343 & -2.00 & $1 \times 10^{-2}$ \\
4 & 363 & -1.3748 & $4.2 \times 10^{-2}$ \\
\hline
\end{tabular}


Table 1d. Thermodynamic equilibrium constants of equilibrium reactions of Oxalate ion with Iodide loaded resin at various temperatures

\begin{tabular}{cccc}
\hline & & \multicolumn{2}{c}{ Thermodynamic equilibrium constant } \\
\cline { 3 - 4 } S. No. & Temp K & $\log \mathrm{K}$ & $\mathrm{K}$ \\
\hline 1 & 303 & -4.7369 & $1.833 \times 10^{-5}$ \\
2 & 323 & -3.6655 & $2.16 \times 10^{-4}$ \\
3 & 343 & -2.9655 & $1.08 \times 10^{-3}$ \\
4 & 363 & -1.1474 & $7.1 \times 10^{-2}$ \\
\hline
\end{tabular}

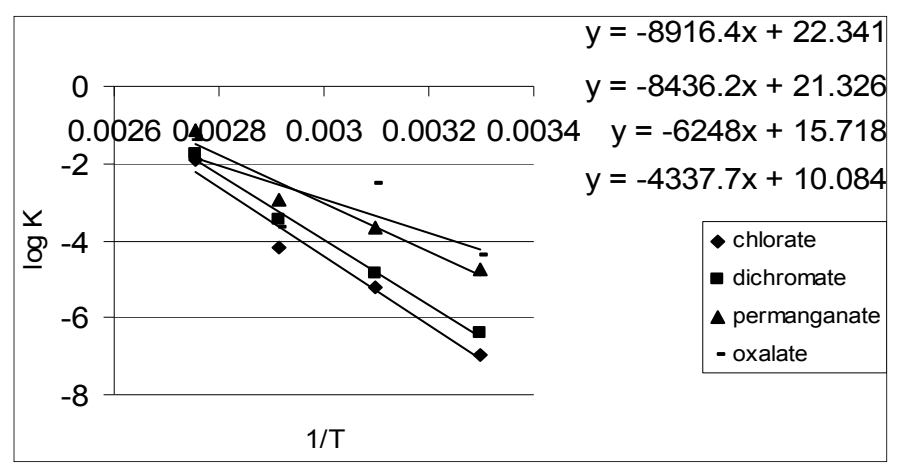

Figure 4. Estimation of enthalpy of exchange reactions of Iodide form of resin with multi atomic anions

Also the enthalpy of the exchange reaction $(\Delta \mathrm{H})$ was calculated using Gibbs Helmholtz equation based on the relation between the variation of $\mathrm{K}_{\text {ther }}$ with temperature and the enthalpy of the reaction. Figure 4 shows the plot of $\log K_{\text {ther }}$ against $1 / T$ to obtain the enthalpy of exchange reactions between Iodide form of the ion exchanger with multi atomic anions.

\section{Results and Discussion}

\subsection{Study of Mechanism of Exchange of Iodide Form of Resin With Multi Atomic Anions}

From Figure 1, we find that the \% regeneration of Iodide to vary between 0-5, 1.5-6.9, 3-9.2, 5.1-12.8 from 10 to 40 minutes before interruption using chlorate, dichromate, permanganate and Oxalate. After interruption for 20 minutes, the \% regeneration was found to change from 5-9.5, 6.9-12, 9.2-15.4, 12.8-20.4 from 60 minutes to 90 minutes using chlorate, dichromate, permanganate and Oxalate. The slopes of the \% regeneration vs timing before and after interruption are found to be $0.16 \& 0.15$ for chlorate, $0.18 \& 0.17$ for dichromate, $0.20 \& 0.21$ for permanganate and $0.256 \& 0.253$ for Oxalate which indicates the slope before and after the interruptions are almost the same giving credence to the film diffusion mechanism (Helfferich, 1962).

\subsection{Extent of Regeneration}

The exchange capacity of resin was found out to be $0.616 \mathrm{~m} . \mathrm{eq} / \mathrm{g}$.

From Figure 2a, the \% regeneration of Iodide loaded resin was found to vary between $0.065-5.7,0.35-12$, $1.3-12.6$ and $9-15.3$, at $303 \mathrm{~K}, 323 \mathrm{~K}, 343 \mathrm{~K}$ and $363 \mathrm{~K}$ using the chlorate solutions of strength corresponding to $100-500 \%$ stoichiometry with respect to exchange capacity. The respective line equations are $\mathrm{y}=0.0111 \mathrm{x}-1.115$, $\mathrm{y}=0.0144 \mathrm{x}-7.96, \mathrm{y}=0.0286 \mathrm{x}-2$ and $\mathrm{y}=0.0278 \mathrm{x}-4.17$ for $303 \mathrm{~K}, 323 \mathrm{~K}, 343 \mathrm{~K}$ and $363 \mathrm{~K}$. Regression analysis of the data shows that the coefficient of determination, $\mathrm{R}^{2}$ are $0.9868,0.8784,0.8362,0.8672$ at $303 \mathrm{~K}, 323 \mathrm{~K}$, $343 \mathrm{~K}$ and $363 \mathrm{~K}$.

From Figure $2 b$, the \% regeneration was found to vary between $0.6-8.9,1.9-9.5,4.7-11.1$ and 13.4-17.3 at $303 \mathrm{~K}$, $323 \mathrm{~K}, 343 \mathrm{~K}$ and $363 \mathrm{~K}$ using dichromate solutions of strength corresponding to $100-500 \%$ stoichiometry with respect to exchange capacity. The respective line equations are $\mathrm{y}=0.0204 \mathrm{x}-1.687, \mathrm{y}=0.02 \mathrm{x}-0.02, \mathrm{y}=$ $0.0203 x+2.37$ and $y=0.0098 x+12.3$ for $303 \mathrm{~K}, 323 \mathrm{~K}, 343 \mathrm{~K}$ and $363 \mathrm{~K}$. Regression analysis of the data shows that the coefficient of determination, $\mathrm{R}^{2}$ are $0.3847,0.9939,0.9392$ and 0.9848 at $303 \mathrm{~K}, 323 \mathrm{~K}, 343 \mathrm{~K}$ and 363 $\mathrm{K}$. 
From Figure 2c, the \% regeneration was found to vary between 1.47-20, 2.13 to $20.1,4.6-21$ and 20.9-21.25 at $303 \mathrm{~K}, 323 \mathrm{~K}, 343 \mathrm{~K}$ and $363 \mathrm{~K}$ using the permanganate solutions of strength corresponding to $100-500 \%$ stoichiometry with respect to exchange capacity. The respective line equations are $\mathrm{y}=0.046 \mathrm{x}-3.794, \mathrm{y}=$ $0.0385 \mathrm{x}+2.01, \mathrm{y}=0.0439 \mathrm{x}-2.276$, and $\mathrm{y}=0.0019 \mathrm{x}+18.68$, for $303 \mathrm{~K}, 323 \mathrm{~K}, 343 \mathrm{~K}$ and $363 \mathrm{~K}$. Regression analysis of the data shows that the coefficient of determination, $R^{2}$ are $0.9881,0.9564,0.8793$ and 0.8426 at 303 $\mathrm{K}, 323 \mathrm{~K}, 343 \mathrm{~K}$ and $363 \mathrm{~K}$.

From Figure $2 \mathrm{~d}$, the \% regeneration was found to vary between $0.75-45,2.4-48.5,4.2-53.5$ and $20.7-71.3$, at 303 $\mathrm{K}, 323 \mathrm{~K}, 343 \mathrm{~K}$ and $363 \mathrm{~K}$ using oxalate solutions of strength corresponding to $100-500 \%$ stoichiometry with respect to exchange capacity. The respective line equations are $\mathrm{y}=0.1042 \mathrm{x}-15.81, \mathrm{y}=0.1093 \mathrm{x}-13.97, \mathrm{y}=$ $0.1297 \mathrm{x}+7.81$ and $\mathrm{y}=0.1274 \mathrm{x}-13.06$ for $303 \mathrm{~K}, 323 \mathrm{~K}, 343 \mathrm{~K}$ and $363 \mathrm{~K}$. Regression analysis of the data shows that the coefficient of determination, $\mathrm{R}^{2}$ are $0.0296,0.9705,0.9972$, and 0.9878 at $303 \mathrm{~K}, 323 \mathrm{~K}, 343 \mathrm{~K}$ and 363 $\mathrm{K}$.

From Figures 2a-2d, we find that the percentage regeneration of Iodide form of the resin into multiatomic anionic forms increases with increase in the strength of the multi atomic ionic solution. Also the percentage regeneration was found to increase with temperature. As the strength of the multi atomic anionic increases from 6.16-30.80 mN, the available multi atomic anions in $100 \mathrm{~mL}$ of the solution increases from 0.616 to $3.080 \mathrm{~m}$.eq. As the exchange capacity was found to be $0.616 \mathrm{~m} . \mathrm{eq} / \mathrm{g}$, the amount of multi atomic anions needed for $100 \%$ conversion of $1 \mathrm{~g}$ of the resin is $0.616 \mathrm{~m}$.eq. Since the availability of multi atomic ions was more with its concentration, the percentage regeneration was found to increase with strength of the solution.

The coefficient of determination, $\mathrm{R}^{2}$ gives the proportion of the variance (fluctuation) of one variable that is predictable from the other variable. Analysis of the coefficient of determination of the variation between the percentage regeneration with \% stoichiometry of the exchanging ions at different temperatures shows that the data are more linear at higher temperatures as the coefficient of determination values are more than 0.8 at higher temperatures in all the cases.

The charge to radius ratios of the anions chlorate, dichromate, permanganate and oxalate are $0.00166,0.001873$, 0.001976 , and 0.003778 . The radius ratio for Iodide is 0.01053 . The ionic potential, the charge to radius ratio of the ions follow the sequence

\section{Oxalate $>$ Permanganate $>$ dichromate $>$ chlorate,}

We find that the exchange of Iodide form of resin with the multi atomic anions also follow the same sequence.

\subsection{Effect of Temperature on Equilibrium Constant}

More rigorous calculations were made by including the activity coefficients of the counter ions in the solution to compute the thermodynamic equilibrium constant (Lokande \& Singare, 2001; Walton et al., 1961). The ion exchange reactions were utilized for the determination of activity coefficients in mixed electrolytes (Vanselow, 1932), thermodynamic calculation of cation exchange selectivities (Boyd, 1956) and equilibrium constants of cation exchange processes (Argersinger, 1952) and for estimation of enthalpy of exchange reactions of uni bivalent ions (Bonner \& Pruett, 1959).

The ion exchange reaction at equilibrium may be represented as

$$
\begin{aligned}
\mathrm{RI}+\mathrm{ClO}_{3}^{-} & \longrightarrow \mathrm{RClO}_{3}+\mathrm{I}^{-} \\
2 \mathrm{RI}+\mathrm{Cr}_{2} \mathrm{O}_{7}{ }^{2-} & \longrightarrow \mathrm{R}_{2} \mathrm{Cr}_{2} \mathrm{O}_{7}+2 \mathrm{I}^{-} \\
\mathrm{RI}+\mathrm{MnO}_{4}^{-} & \longrightarrow \mathrm{RMnO}_{4}+\mathrm{I}^{-} \\
2 \mathrm{RI}+\mathrm{C}_{2} \mathrm{O}_{4}{ }^{2-} & \longrightarrow \mathrm{R}_{2} \mathrm{C}_{2} \mathrm{O}_{4}+2 \mathrm{I}^{-}
\end{aligned}
$$

The apparent equilibrium constant was calculated using the equation:

$$
\begin{aligned}
\mathrm{K}_{\text {app }} & =\left[\mathrm{RClO}_{3}\right]\left[\mathrm{I}^{-}\right] \mathrm{f}_{\mathrm{I}}^{-} /[\mathrm{RI}]\left[\mathrm{ClO}_{3}^{-}\right]^{\mathrm{f}} \mathrm{ClO}_{3}^{-} \\
\mathrm{K}_{\text {app }} & =\left[\mathrm{R}_{2} \mathrm{Cr}_{2} \mathrm{O}_{7}\right]\left[\mathrm{I}^{-}\right]^{2} \mathrm{f}_{\mathrm{I}}^{-12} /[\mathrm{RI}]^{2}\left[\mathrm{Cr}_{2} \mathrm{O}_{7}{ }^{2-}\right]^{\mathrm{f}} \mathrm{Cr}_{2} \mathrm{O}_{7}{ }^{2-} \\
\mathrm{K}_{\text {app }} & =\left[\mathrm{RMnO}_{4}\right]\left[\mathrm{I}^{-}\right] \mathrm{f}_{\mathrm{I}}^{-} /[\mathrm{RI}]\left[\mathrm{MnO}_{4}\right]^{\mathrm{f}} \mathrm{MnO}_{4}^{-} \\
\mathrm{K}_{\text {app }} & =\left[\mathrm{R}_{2} \mathrm{C}_{2} \mathrm{O}_{4}\right]\left[\mathrm{I}^{-}\right]^{2} \mathrm{f}_{\mathrm{I}}^{-12} /[\mathrm{RI}]^{2}\left[\mathrm{C}_{2} \mathrm{O}_{4}{ }^{2-}\right]^{\mathrm{f}} \mathrm{C}_{2} \mathrm{O}_{4}{ }^{2-}
\end{aligned}
$$

Where RI refers to the amount of $\mathrm{I}^{-}$in the resin phase and $\left[\mathrm{I}^{-}\right]$refers to the amount of Iodide concentration in the solution phase respectively. The $\mathrm{f}_{\mathrm{s}}$ represent the activity coefficients of the ions in the solution phase. 
$\log \mathrm{K}_{\text {app }}$ was plotted against equilibrium concentration of multi atomic anions in the solution which was extrapolated to zero equilibrium concentration of multi atomic anions to get $\mathrm{K}_{\text {th }}$ for the exchange reactions of Iodide form of the resin. The activity coefficient of the ions (f) in the solution phase was computed from the Debye Huckel limiting law

$$
\log =-A \sqrt{ } \mu Z^{2}
$$

where $\mu$ is the ionic strength given by

$$
\mu=1 / 2 \Sigma \mathrm{c}_{\mathrm{i}} \mathrm{z}_{\mathrm{i}}^{2}
$$

where $\mathrm{Zi}_{\mathrm{i}}$ and $\mathrm{c}_{\mathrm{i}}$ are the charge and concentration of the ion and $\mathrm{A}$ is the Debye Huckel constant.

\subsection{Effect of Temperature on the Equilibrium Constant in the Exchange of Iodide Loaded Resin With Multi Atomic Anions}

Figure 3a, the plot of $\log \mathrm{K}_{\mathrm{app}}$ vs equilibrium strength of chlorate ion at different temperatures for chlorate as regenerant for exchange with Iodide form of resin give rise to straight lines with equations $y=0.1462 \mathrm{x}-6.9701, \mathrm{y}$ $=0.1048 \mathrm{x}-5.2065, \mathrm{y}=0.1034 \mathrm{x}-4.1561$ and $\mathrm{y}=0.0518 \mathrm{x}-1.8873$ showing the thermodynamic equilibrium constants as $1.07 \times 10^{-7}, 6.215 \times 10^{-6}, 6.98 \times 10^{-5}$ and $1.30 \times 10^{-2}$ at $303,323,343$ and $363 \mathrm{~K}$.

Figure $3 b$, the plot of $\log K_{\text {app }}$ vs equilibrium strength of dichromate ion at different temperatures for dichromate as regenerant for exchange with Iodide form of resin give rise to straight lines with equations $\mathrm{y}=$ $0.3667 x-6.4158, y=0.2687 x-4.8612, y=0.18 x-3.4486$ and $y=0.0802 x-1.7597$ showing the thermodynamic equilibrium constants as $3.83 \times 10^{-7}, 1.37 \times 10^{-5}, 3.55 \times 10^{-4}, 1.7 \times 10^{-2}$ at $303,323,343$ and $363 \mathrm{~K}$.

Figure 3c, the plot of $\log \mathrm{K}_{\text {app }}$ vs equilibrium strength of permanganate ion at different temperatures for permanganate as regenerant with Iodide form of resin give rise to straight lines with equations $\mathrm{y}=$ $0.3023 \mathrm{x}-4.4032, \mathrm{y}=0.1762 \mathrm{x}-2.5438, \mathrm{y}=0.2512 \mathrm{x}-3.6815$ and $\mathrm{y}=0.0964 \mathrm{x}-1.3748$ and showing the thermodynamic equilibrium constants as $3.9 \times 10^{-5}, 2.8 \times 10^{-3}, 1.04 \times 10^{-2}$ and $4.2 \times 10^{-2}$ at $303,323,343$ and $363 \mathrm{~K}$.

Figure $3 \mathrm{~d}$, the plot of $\log \mathrm{K}_{\text {app }}$ vs equilibrium strength of oxalate ion at different temperatures for oxalate as regenerant for Iodide form of resin give rise to straight lines with equations $\mathrm{y}=0.1429 \mathrm{x}-4.7369, \mathrm{y}=$ $0.1073 \mathrm{x}-3.6655, \mathrm{y}=0.0917 \mathrm{x}-2.9655$ and $\mathrm{y}=0.041 \mathrm{x}-1.1474$ showing the thermodynamic equilibrium constants as $1.833 \times 10^{-5}, 2.16 \times 10^{-4}, 1.08 \times 10^{-3}, 7.1 \times 10^{-2}$ at $303,323,343$ and and $363 \mathrm{~K}$.

From Figures $3 \mathrm{a}-3 \mathrm{~d}$, we observe that the equilibrium constant of the exchange reaction was observed to be more with temperature

\subsection{Enthalpy of Ion Exchange Reactions}

In order to get the enthalpy of the exchange reaction, use is made of the Gibbs Helmholtz relation between the variation of equilibrium constant with temperature and the enthalpy of the reaction given by

$$
\mathrm{d} \ln \mathrm{K} / \mathrm{dT}=\Delta \mathrm{H} / \mathrm{RT}^{2}
$$

Which in the integrated form gives

$$
\log \mathrm{K}=-\Delta \mathrm{H} / 2.303 \mathrm{RT}+\mathrm{C}
$$

The line equations in the plot of $\log \mathrm{K}_{\text {th }} \mathrm{Vs} 1 / \mathrm{T}$ are $\mathrm{y}=-8916 \mathrm{x}+22.34, \mathrm{y}=-8436 \mathrm{x}+21.36, \mathrm{y}=-6248 \mathrm{x}+15.72$, and $y=-4337.7 x+10.084$ for chlorate, dichromate, permanganate and Oxalate (Figure 4) respectively. Also the regression analysis shows that the coefficient of determination $\mathrm{R}^{2}$ between $1 / \mathrm{T}$ against log (equilibrium constant) using chlorate, dichromate, permanganate and Oxalate are $0.9988,0.9768,0.9993$ and 0.9819 respectively indicating that the equilibrium constant variation with temperature is linear.

From the slopes of the line (Figure 4) the exchange reactions were found to be endothermic with enthalpies $170.79 \mathrm{KJ} /$ mole for chlorate, $161.59 \mathrm{KJ} /$ mole for dichromate, $119.68 \mathrm{KJ} /$ mole for Permanganate and 83.07 $\mathrm{KJ} /$ mole for Oxalate.

\section{Conclusion}

Ion exchange reactions between Iodide form of resin with multi atomic anions viz. chlorate, dichromate, permanganate and Oxalate etc. were carried out at various temperatures. The order of exchange of Iodide form of resin with multi atomic anions follows the sequence

$$
\text { Oxalate }>\text { permanganate }>\text { dichromate }>\text { chlorate }
$$

Results indicate that the reactions are endothermic, favoring the exchange reactions at higher temperatures. 


\section{Acknowledgments}

The authors express their thanks to Shri Biplob Paul, Shri B. Sreekumar, Plant Supdts, for the valuable discussions and Shri. S. Ramachandran and K. Elumalai for their assistance in the experimental work.

\section{References}

Argersinger, W. J, \& Davidson, A. W. (1952). Equilibrium constants of cation exchange processes. J. Phys. Chem., 56, 92. http://dx.doi.org/10.1021/j150493a018

Boyd, G. E., \& Myers, G. (1956). A thermodynamic calculation of cation exchange selectivities. J. Phys. Chem., 60, 521. http://dx.doi.org/10.1021/j150539a003

Helfferich, F. (1962). Ion exchange. Mc-Graw Hill Book Company.

Kubota. (1983). Decomposition of a cation exchange resin with hydrogen peroxide. J. of Radio Analytical Chemistry, 78, 295-305.

Lokande, R. S., \& Singare, P. U. (2001). Study on Ion Exchange Equilibria involving $\mathrm{I}^{-} / \mathrm{SO}_{4}{ }^{2-}$ and $\mathrm{I}^{-} / \mathrm{C}_{2} \mathrm{O}_{4}{ }^{2-}$ Uni-Bi valent Ion exchange systems. Asian Journal of Chemistry, 13, 43-39.

Mozes, M. (1982). Volume reduction of spent ion exchange resin by acid digestion. Nuclear Technology, 59, 270.

Plecas, I. B, Pavlovic, R. V. (2003). Leaching of Co-60 and Cs-137 from spent ion exchange resins in cement-bentonite clay matrix. Bulletin of Material Science, 26, 699-701. http://dx.doi.org/10.1007/BF02706766

Vanselow, A. P. (1932). The utilization of the base exchange reactions for the determination of activity coefficients in mixed electrolytes. J. Am. Chem. Soc., 54, 1307. http://dx.doi.org/10.1021/ja01343a005

Vogel, A. I. (1978). Text book of quantitative inorganic analysis, 368, 372.

Walton, H. F., Jordon, D. E., Samady, S. R., \& Mckay, N. (1961). Cation exchange equilibria with divalent ions. J. Phys. Chem., 65, 1477. http://dx.doi.org/10.1021/j100905a002

\section{Copyrights}

Copyright for this article is retained by the author(s), with first publication rights granted to the journal.

This is an open-access article distributed under the terms and conditions of the Creative Commons Attribution license (http://creativecommons.org/licenses/by/3.0/). 